\title{
SPINNING A CONFLICT MANAGEMENT WEB IN VANAUTU: CREATING AND STRENGTHENING LINKS BETWEEN STATE AND NON-STATE LEGAL INSTITUTIONS
}

\author{
This is a working paper version of a paper published in (2011) 63 Journal \\ of Legal Pluralism and Unofficial Law 179-205
}

\section{Miranda Forsyth}

Conflict management is done by both state and non-state institutions in Vanuatu, a small archipelago situated in the region known as Melanesia in the South Pacific. Each institution has a range of different resources available to it, for example, customary institutions in general are rich in human resources and legitimacy, while the state justice system has significantly greater financial and coercive resources. However, for a variety of reasons expounded upon below, both state and non-state institutions are failing to satisfactorily meet the conflict management needs of Vanuatu citizens (Forsyth 2009). ${ }^{1}$ Given the current spread across institutions of the resources necessary to manage disputes, and the lack of capacity for any one institution to monopolise these in the near future, any international donor interested in undertaking reform in this area must actively engage with both state and non-state institutions and actors. This reality of legal pluralism can provoke a number of responses. One is to attempt to harness the resources of the non-state system by bringing it within the apparatus of the state system (see for example Huyse and Salter 2008), and another is to create a new hybridized system that merges state and nonstate orders (see for example Walker and Garu 2009, Boege et al 2008). This article proposes a third approach: to build or reinforce existing linkages between all state and non-state institutions and actors that are currently involved in conflict management (see also Baker 2010: 598).

The creation of linkages can have a number of advantages over subordination or hybridization. First, it responds to the idea of harnessing voluntary and legitimate social ordering and only resorting to state sanctions when this fails (Braithwaite 2002:29). Second, it recognises that state forms of ordering themselves need to be subjected to oversight by other social institutions, and thus in a healthy regulatory system, mutual monitoring is both necessary and legitimate. Third, linkages can facilitate a more efficient sharing of resources between institutions and actors, whilst leaving space for each to perform the role that it does best. Fourth, linkages can promote dialogue about existing or potential conflicts of agenda in a non-hierarchical way, leaving more room for creative compromises than if a top-down approach is

\footnotetext{
${ }^{1}$ The term conflict management is used in this article as it is broad enough to include processes which go beyond dealing merely with particular disputes, thus allowing a study "of the relationship of rule orders to behaviour" (Chanock 2000: xviii). The phrase 'justice' is also avoided because it carries with it connotations associated with western 'justice' systems, such as the importance of individual rights, consistency in judgments, a fair and open trial, impartial judges and the right to present a defence. As discussed below, in countries such as Vanuatu, these may not be the priorities of conflict management and concepts such as the re-establishment of peace and harmony in the community and the restoration of relationships may be prioritised. The use of the term "justice" may mask these fundamental differences in agenda, creating the assumption that all systems are reading from the same page when there might be considerable divergence of opinion in what priorities to be pursued.
} 
adopted. Fifth, linkages can facilitate different orders learning from the other, which can raise standards and legitimacy on both sides (Baker 2010: 609; Forsyth 2009: 225-238). While the end result of this may well be a hybridized system, it will have been achieved in an organic manner, driven by the needs and experiences of the actors involved, rather than having had its form pre-determined from the start. Focussing on linkages is thus in many ways more a philosophy about how to go about doing reform and development in pluralist countries, than a reform program with a particular goal, such as improving access to justice, gradual compliance with international human rights, or building strong and legitimate institutions. The central argument of this article is therefore that, regardless of the specific reform objectives involved, adopting an approach that focuses on strengthening linkages between the actors and institutions actually involved in a particular field will result in greater home-grown, legitimate and sustainable change in legally plural countries. The focus in this article is on conflict management, but the general approach could be more widely applied.

The first section of the article briefly outlines the current legal environment in Vanuatu, focussing on the relationship between the state and non-state conflict management providers, and demonstrating the importance of better links between them in building more effective and legitimate conflict management. The second section demonstrates the potential of different sorts of links between the state justice system and customary actors and institutions. It reflects on a number of initiatives that have taken place in Vanuatu in the past five years at both national and local levels, which have been initiated by the state, non-state actors, international donors and academics.

Section three then introduces a new conceptual framework to assist international donors and state and non-state actors in creating such links, and also in developing, managing and aligning reform initiatives. The framework proposed is that of a 'conflict management web' that joins together different actors, institutions, systems and sub-systems through multiple linkages both within and outside a country. Such an approach requires a holistic view (Scott 2001: 332) to be taken of any reform project in this field. This entails prioritising co-ordination with other projects, and making strategic alignment of the reform agenda with the interests and needs of key stakeholders in both state and non-state sectors central to the project design. A conflict management web approach also emphasizes the importance of developing multiple linkages between state and non-state actors, donors and others: if one link breaks there are numerous others to bind the web together, and even if each link is individually weak, together they can be strong (Granovetter 1973 1985; Braithwaite 2008: 201). Moreover, a conflict management web would support incremental reform projects, useful where there are not the financial resources or political will for large scale institutional reform (Gupta 2002: 379). The conflict management web approach finds support in the arguments used by Baker to support as 'multi-layered' approach to policing and justice (this issue). It develops these ideas further by positioning the creation of linkages between conflict management providers in-country and external sources of support (donors, academics, NGOs) at the heart of the analysis about how to improve conflict management. The final section of this article will more fully describe the web framework and discuss its implications for those involved in reform in legally plural countries. 


\section{The Vanuatu Legal Environment ${ }^{2}$}

Conflict management in Vanuatu is mostly delivered by the state and the customary system of conflict management, referred to in Vanuatu as the kastom system. ${ }^{3}$ Although the churches also play a minor role in conflict management, their role has not as yet been the subject of fieldwork, and so only state and kastom are discussed in this article. The state system of conflict management is based on English and French models introduced during colonial times (1901-1980) and comprises western-style laws and institutions. As a whole it currently faces a number of challenges, including chronic under-resourcing, slowness, limited geographical reach (particularly problematic given that the population is dispersed over numerous islands, some of which have no police post and many no court), human rights abuses and a lack of legitimacy as a result of being based upon a foreign system (Forsyth 2009: 166). As a result, the state alone is currently unable to provide its citizens with acceptable levels of conflict management, or personal security. For example, the Police Commissioner stated in 2011 (Marango 2011: 3) "[the] Vanuatu Police Force has a limited budget and can only do a portion of its part in sustaining security in Vanuatu."

The kastom system, in contrast, exists in one form or another throughout Vanuatu. It handles the vast majority of conflicts in every rural and urban community (Forsyth 2009: 97). The central idea of kastom is that the chief or chiefs of a community are responsible for managing disputes within their areas of authority. ${ }^{4}$ They do so by holding public meetings with the parties involved in the disputes where the dispute is discussed, responsibility allocated and amends made through the payment of a fine, in the form of mats, kava, food, pigs, cows and increasingly cash, by one or both of the parties.

The kastom system throughout the country is incredibly diverse, but it is possible to identify several core principles. These allow ni-Vanuatu to distinguish 'their' system from the state system, even while separating their particular version of kastom from that of a different part of the country. For example, the Secretary of the National Council of Chiefs (NCC), in the context of a protest about prison conditions in which the prisoners had fled to the NCC for protection, stated on the radio (Pacific Beat 2006):

We made a ceremony and then the Chiefs handed the prisoners over to the other system of governance, that's the police again. So, it was really from one system to the other and making sure that both systems, protocols, procedures, are observed in the whole process. Yesterday, we believe that

\footnotetext{
${ }^{2}$ This description is based upon fieldwork conducted in Vanuatu between 2002 and 2008. For a more detailed account see Forsyth (2009).

${ }^{3}$ Although the use of the term 'system' may be criticised in a number of respects including for being misleading because it implies a coherence and structure that the kastom system does not have, I have defended the use of the term elsewhere (Forsyth 2009: 95-96). Space does not permit a re-discussion of this point, save to note the concluding reason I gave for using it, namely that the "the kastom system is conceived of as such by many involved in its administration." (ibid.)

${ }^{4}$ Chiefs are the heads of particular communities and gain their positions through a variety of mechanisms including blood line, election and ability (Forsyth 2009: 61). Generally an individual chief will deal with a minor matter and more serious matters or 'appeals' are dealt with by a council of chiefs (ibid.: 99).
} 
we observed the two procedures for the two systems and we feel that we are quite satisfied with what we've done yesterday [my emphasis].

An underlying principle of the kastom system as enunciated by the chiefs and as practiced in the vast majority of cases, is that it is restorative. This means that dispute resolution is focused on restoring those relationships that have been broken by the disputes. Two of the main aims of any kastom meeting are: blong mekem [tufala pati] shake han mo kam gudfala fren bakegen (to make the two parties shake hands and become good friends again), and to allow the defendant to mekem gud fes (literally 'clean (the person's) face' so as to regain respect in the community). The purpose of this second aim is to allow the defendant to once again become a functioning member of the community.

However, at times the restorative principles are not followed and the kastom system is used as a means of punitive control. An example of this is given by a youth in Port Vila in 2007 who stated (Forsyth 2009: 108):

I will tell you about a case of a relative of mine. She had "flatem" [had sexual intercourse with] all the men around her and made lots of women very angry with her. The chiefs tried everything they could to stop her - they cut off her hair, and they all whipped her. Then finally they sent her back to the island. She stayed there for ten years and she saw how hard life was there, not like getting paid money for sex, and now she has come back to Vila ten years later a changed woman. Now she stands next to the chiefs to assault the women who have children with no fathers!

Another central principle of the kastom system is that of restoring peace and harmony to the community. At times this principle conflicts with the restorative notions of the kastom system; for example victims who may not really be happy with the decision are forced to accept it and "shake hands" for the good of the community. This principle may also conflict with notions of individual rights as the peace of the community is prioritised over individual justice. Thus, the aims of conflict management differ quite significantly between kastom and the state justice system.

While the kastom system resolves the majority of disputes, it also faces significant challenges, largely as a result of Vanuatu's development as a nation state from what was a stateless society, and the pressures of rapid social change over the past decade as a result of globalisation. For example, there has been a shift from a kastom based traditional economy, over which chiefs had a great deal of control, to a cash economy; and the population is increasingly mobile, which takes people out of the sphere of influence of their chief. Chiefs regularly complain that people refuse to listen to their orders, to come to meetings or pay the fines levied upon them. In addition, community members challenge the chiefs on the basis that they have no authority under the Constitution; the police prevent chiefs from using force to enforce their orders; and people take disputes to the state system if they are not satisfied with the chiefs' decision, thus undermining their authority. Another difficulty associated with the kastom system today is that in many places it discriminates against women and youth, both procedurally by denying them a voice and also substantively, for example by fining a woman more than a man in a case of adultery. There is also a widespread perception that some chiefs are biased, and even more problematically, there is no real 
way of dealing with biased, unfair, lazy or incompetent chiefs. As a result, many niVanuatu face the dilemma of believing in the kastom system and its advantages, but not being able to benefit from it because of the character of their particular chief.

Despite these challenges, the kastom system is generally well-supported by the population today, including by women and youth. People appreciate its many benefits, including its essentially restorative nature, its geographic and financial accessibility; its familiarity; its ability to bring about peace and the fact that it is 'their' system.

\section{The relationship between kastom and the state system}

Since colonisation, ni-Vanuatu have thus been faced with at least two systems of conflict management that they can draw upon, depending upon particular circumstances (such as the accessibility and strength of both in a particular location) as well as personal preferences (such as support for or mistrust in kastom chiefs, the state, or the colonial powers, and beliefs about which system will lead to a more advantageous outcome). The legitimate scope of the two systems has never been formalised, instead the unofficial division of jurisdiction has been left to individual institutions and administrators to negotiate. The results of this process have and do vary considerably over time and place (Forsyth 2009: 139-174). Until very recently (as discussed below) there was little active dialogue between the two systems, or interchange of different legal views. This was due in part to the lack of centralisation of the kastom system, endemic political instability and the difficulties of communication in Vanuatu generally, and also to the lack of institutional spaces for such dialogue to occur. During the colonial period, District Agents and Assessors were formally charged with liaising between the two systems, and found themselves confronted with particular situations requiring them to reconcile procedural and substantive differences between the two systems. With independence, such roles disappeared, and with them the opportunity for conflicts between the systems to arise and be articulated on the level of legal principle.

The current linkages between the systems are thus largely informal, dynamic and subject to continuous negotiation. Although this means that the relationship can easily adapt in response to the needs of each particular system and to define its own norms and procedural framework, it leads to unrestricted forum shopping and is problematic in many other respects. Among these are, for example: the feeling that a complainant could have got a better outcome with the 'other' system (however ill-founded) undermines reconciliation processes; confusion about which disputes should be dealt with where and with actors in both systems trying to avoid responsibility for difficult cases, such as those involving domestic violence by claiming the other system is responsible; and situations where people refuse to obey chiefly orders, claiming that they will 'appeal' to the state and the chief has no real authority (see Forsyth 2007: 175-197, 254).

An increasing cause of tension is the state's heavy reliance upon the kastom system, especially in rural areas, coupled with its reluctance to contribute any resources or recognition in return. The chiefs are becoming tired of being treated as the unpaid and unacknowledged assistants of the state system, and are increasingly vocalising demands for legislative recognition of chiefly powers. In the past, the state system has been able to brush off such demands by trotting out platitudes about the authority and 
power of the chiefs resting in community respect. However, $t$ is unlikely that this response will be tenable for much longer, especially given the evidence that community respect is partially unravelling for the chiefs.

Thus we can see that both the state justice system and the kastom system are vital for ensuring conflicts are managed in an effective and legitimate way in Vanuatu. However, each system is currently facing significant challenges, its operation undermines the other in many respects, and they are largely missing out on the opportunity to be enriched by, and learn from, each other. ${ }^{5}$ Recognition of this means that any justice reform initiative should consider building the capacity and legitimacy of state and non-state systems, as supporting one to the exclusion of the other is unlikely to be effective (OECD 2007: 17). One way to do this is to develop linkages between all relevant systems, for the reasons outlined in the introduction to this article. Baker (2010: 609) also argues that this "offers the opportunity of state oversight according to defined standards and within an affordable national budget, whilst at the same time linking state systems to non-state providers who may well enjoy local ownership, sustainability and effective procedures." Investigating how such linkages might be created is the subject of the next section.

\section{Initiatives linking state and kastom in Vanuatu}

In the past five years there have been a number of initiatives that have forged, or attempted to forge, closer links between the state and kastom systems, although this has not necessarily been the primary or even articulated goal of the initiative. This part will demonstrate the interest in such links by actors in both state and kastom systems, and the important role that can be played by donors and academic institutions in facilitating the building of such links. It will also highlight some of the challenges involved in the creation of such links.

\section{Kastom-generated links}

\section{(a) National Legislation}

The NCC has become increasingly proactive in the past eight years in seeking to organise the different levels of chiefly councils and to get the state to assist chiefs with enforcing their authority, such as making people pay kastom fines. To this end, a National Council of Chiefs Bill was drafted, largely by the NCC but with assistance from a law professor, to set out the roles and powers of chiefs. When the Bill reached parliament in 2006 it was debated for two days, and was amended to such an extent that it did not result in any real increased recognition of chiefly powers by the state. The only significant change was to give the NCC the authority to reshape existing island and urban councils of chiefs. To date its efforts to do this have met with mixed success. ${ }^{6}$ The Secretary of the NCC commented that the Act as finally enacted by parliament was like a dog that had had all its teeth removed and yet was still expected to go and hunt pigs (Forsyth 2006).

\footnotetext{
${ }^{5}$ For a detailed analysis of the way in which each is undermining the other see Forsyth (2009:182-196).

${ }^{6}$ For example, the Port Vila council of chiefs was dissolved in 2007 amid significant disagreement.
} 
This exercise demonstrates the extremely contentious and politicised nature of discussions over chiefly powers in Vanuatu. It also shows that although state leaders may make general statements about the importance of traditional leaders and kastom, when it comes to engaging in any real power sharing then they are reluctant to give any responsibility away, and so this is a process that involves much time and dialogue. Although the highly contested nature of these issues does make it difficult for donors to become engaged, there is a potentially very useful role for them in funding research and workshops to assist in making sure the debates are as informed as possible. It is likely that much more could have been achieved with the Bill if there had been more support for the NCC in preparing and workshopping the legislation with those involved in the state justice system (police, prison officers, prosecutors, judges, Ministry of the Justice officials etc) , as well as with interest groups, such as those representing women and youth, before presenting it to parliament.

\section{(b) Kastom Governance Partnership Project.}

The Kastom Governance Project was initiated following an informal meeting between the Secretary of the NCC and a member of Australian Centre for Peace and Conflict Studies (ACPACS), and then Australian Development Agency (AusAID) was brought in as a donor in 2005 (ODE 2010: 13). The overall aim of the project (ODE 2010: 28) is to support kastom so as to "support the way of life of Ni-Vanuatu: environmental sustainability, economic prosperity, peace, justice, equity." The central activities of the project are research on aspects of the kastom governance system by ACPACS and storians (workshops) which facilitate dialogue on kastom leadership, change, development and conflict resolution between chiefs, community leaders, women and youth representatives, provincial government officials and police. The storians also involve creating action plans to put into practice some of the ideas generated at the workshop. A project leader (Westoby 2010: 15) describes these storians as being "structured contexts for facilitated conversations around questions that community leaders regularly face but rarely have an opportunity to work through together in a reflective context. That is, they are understood as 'difficult conversations' that could lead to innovative action."

Although hampered by delays caused by a variety of internal process problems, the kastom governance project offers a number of positive lessons in how external agencies such as a university can assist a non-state system to contribute to conflict management. One positive feature of the initiative is the amount of agency that was given to the chiefs in the design and operation of the project. The project design was based upon "a year of conversation" (Westoby and Brown, 2007: 77-78) during which time, trust and mutual respect was established between ACPACS and the NCC. Since then, the NCC has played an important role in the design of the project. A project developer observed that the project consciously tried to avoid a common mistake in approach to development in the Pacific Islands which involves "teach[ing] them how to 'do' our institutions better" and instead to recognise "communities and customary leaders' efforts to be self-determining - creating spaces that enable people to negotiate ways through the currents of rapid change that enable them to hold what they value" (Westoby 2010: 15, 18). The participatory nature of the project was also enhanced through the training of local facilitators who were gradually given greater and greater responsibility for the implementation of the workshops. The strong sense of ownership of the activities by the NCC, and the facilitator-only role that ACPACS 
assumed, also mitigated much of the risk of AusAID (and the Australian government) being perceived as interfering in such a highly charged political issue (ODE 2010: 34).

The project also illustrates a number of difficulties in working with a non-state system. First, is the difficulty of determining whom to engage with, a particularly difficult question in a decentralised system. The project dealt with this by working through the NCC. However, this was not entirely satisfactory as it privileged those chiefs who are associated with the national system. It also meant that some important community leaders were not involved, and this led to difficulties in the implementation of the action plans (ODE 2010: 22). Second, it demonstrates that a truly participatory design process requires time to establish trust, to build relationships and to discuss how things will be. Third, the implementation of the action plans was found to be "patchy" (ibid.). This illustrates the difficulty of implementing the many good ideas that occur in the relaxed space of a workshop when there is a return to 'real life' and, perhaps, an encounter with a competing political agenda. In order for this to be successful, there needs to be continual support and follow up, as is apparently planned for the next phase (ibid.: 23).

The final challenge is how to support the human rights of marginalised groups such as women and children, whilst at the same time permitting the participants to determine the direction that the workshops and the action plans take. There is a potential for the project to "strengthen a chiefly system that includes practices detrimental to women" (ibid.). This issue will inevitably arise in every discussion about reforming the kastom system because of a widespread belief that traditionally the kastom system was strongly patriarchal and authoritarian. It is therefore common for many chiefs today to blame their lack of authority on the greater rights allowed to women and youth, and to try to shore up their authority by increasing controls over them. Although the anthropological record does not support this belief (Tor and Toka 2004), these views are firmly entrenched and have led to considerable friction when NGOs have come into communities with a rights-oriented training and development agenda. Indeed, a workshop organiser observed that "chiefs often stated in storians that many of these 'development' agents were contributing to, and partly causing, conflict within communities" (Westoby 2008: 50). It is therefore clear that adopting a rigid rights based approach will risk alienating participants and undermining any project. This observation is supported by Merry's study of bulubulu (traditional forgiveness) in Fiji where she found that a rights discourse backfired in a project intending to stop people using bulubulu to avoid prosecution for rape, and led to an increase in bulubulu rape cases and the discrediting of human rights and feminist discourses (Merry 2006: 122).

A better approach is to establish a foundation of trust between participants and facilitators to initiate conversations about gender and youth, giving space for all participants to reflect on the issues raised. Braithwaite (2010) similarly talks about the need to "vernacularise" restorative justice discourse into the language of local traditions in a way that shows respect to those traditions. This will at the very least lead to a more nuanced understanding of the issues involved, and the conflicts can be approached "conversationally rather than coercively." For example, at one workshop I attended the chiefs complained that the youth were causing problems in the community. The youth leader responded by saying that they were frustrated that they had no opportunity to play sport, in particular football, because of lack of space due to 
land disputes. This discussion thus presented the chiefs with the solution of resolving the land dispute and making a football field. Thus, involving as many female and youth community leaders as possible in the design and implementation of projects, as well as encouraging them to attend as participants, helps to ensure different viewpoints are articulated and creative conversations can be had. The use of local facilitators is also an important way to mediate conflicts in a culturally sensitive manner. This follows Braithwaite's (2010) suggestion to train local trainers to have a 'double consciousness' of indigenous ways of thinking about justice and of the global movement for restorative justice.

\section{(c) Local level initiatives by chiefs}

A number of individual chiefs as well as chiefly councils have made moves to amend their local kastom system by incorporating certain features of the state system. The most widespread example of this is the writing down of their kastom laws as so-called 'by-laws' (White and Lindstrom 1994: 229). Such by-laws typically set out the various offences that contravene kastom laws and provide a penalty in terms of livestock or foodstuffs or woven mats. These by-laws are recorded for a variety of reasons, including that if the laws are written down the people cannot question the chiefs" authority - i.e. it is written "in black and white" - and that if a chief goes to court then he has to be able to justify his decision (Forsyth 2009: 106). There are many other examples of deliberate borrowing from the state system, including: the keeping minutes of kastom meetings; the creation of village police; and the introduction of the concept of payment of fees to get chiefs to hear cases. In at least one village there are village police who wear a special uniform and work on behalf of the chief to provide security and to take statements from people making complaints. They say they wear the uniform in order to "mekem spirit blong wok blong mifala strong, igat pawa" (make our work spirit strong and give power). These borrowings are symptomatic of the widespread open-mindedness and willingness to embrace new ideas that exists among chiefs. This attitude is illustrated by one of the by-laws from a ward council in Penama Province which, roughly translated, states:

The Council does not agree that women should wear shorts but we understand that they have the right to so she can wear shorts so long as they come down to her knees and she does not wear them in front of her brother or some other relatives or else she will be fined.

These borrowings are also likely to be in response to a desire to co-opt state power and to enforce chiefly authority. Chiefs often state that they want training and assistance to enable them to leftemap (lift-up) their system. This positive attitude towards change could be capitalised on by international donors in developing a project that seeks to support chiefs in learning about, and adapting and adopting beneficial features of the state justice system in order to enhance the quality of kastom conflict management. As I have argued elsewhere (Forsyth 2009: 225) such adaptations, which will ideally be mutual, will enhance the ability of different actors and institutions to gradually start to all steer conflict management reform in the same direction.

State-generated links 
An important issue in terms of the legitimacy of the state courts is the extent to which kastom payments are taken into account in sentencing for criminal offences. If the courts do not take the kastom penalty into account, the defendants are left with a sense of grievance at having been subjected to two punishments, and the chiefs feel that their work has been overlooked or, worse, undermined. On the other hand, there can be concerns that people merely make kastom payments as a way of 'buying their way out of trouble.'

In 2006 the Penal Code (Amendment) Act was passed. It requires that state courts must take into account any compensation made or due by the offender under kastom as a mitigating factor in sentencing. This changed the previous position, which allowed courts to take kastom into account but did not require them to do so. There are, however, still problems with the way courts take kastom payments into account. ${ }^{7}$ First, the court is not permitted to halt or terminate the proceedings because the kastom system has already dealt with the matter. Second, there is very little inquiry into whether the parties are satisfied with the settlement, or whether or not the payment was appropriate according to the kastom of the relevant area. Further, the courts have hitherto been inconsistent in their approach to determining the extent to which a customary payment can mitigate a criminal sentence. In discussing these inadequacies and highlighting others, Paterson and Jowitt (2008: 47) make the following suggestions for reforming the way courts take kastom into account in sentencing:

First, the judges could, at their annual conference, discuss these issues and resolve that judicial practice will change. Alternatively, a conference or workshop could be convened to discuss these issues and pass resolutions which could be regarded by the courts as expressions of community attitudes. Third, legislation could be enacted to provide guidance for the courts.

This initiative demonstrates that when making linkages between the two systems it can be insufficient to simply outline broad principles and leave it to the stakeholders, who in this case were the judges and lawyers, to implement them on a case-by-case basis. This may lead to disparity and unfairness. Instead what is required is an opportunity for all who will be involved in implementing the new or reformed link to participate in developing a uniform policy, identifying in as detailed a way as possible how it should work. In addition, there must be a built-in evaluation process to follow up on the results of the reform after a certain number of years have passed, so as to determine if it has helped or hindered the particular objective(s) of the initiative.

\section{Donor and other outsider-generated links}

\section{(a) Community Justice Supervisors}

In 2005 the New Zealand Aid Program (NZAID) began a major Correctional Services Project in Vanuatu. The Project devised a number of reform proposals that "create opportunities for linkages between Kastomary processes and the Courts (NZ AID 2005, [34]." It established a taskforce of senior ni-Vanuatu employed in the

\footnotetext{
${ }^{7}$ For an interesting discussion of how other courts in the region have dealt with the issue of taking into account customary remedies see New Zealand Law Commission (2006: 180-184). 
state justice system and the Malvatumauri and held "extensive consultations ... with a number of stakeholders and interest groups in five or the six provinces" (NZ AID 2005, [34]). A central proposal was the establishment of a Community Probation Service which adopts a "Community Justice Process". This process is said to build on and strengthen the Vanuatu tradition of community participation in the justice process and to preserve and enhance the existing practice of chiefs resolving disputes in what the Project refers to as a traditional context. The process is based on the idea that at a number of points there are opportunities for matters to be referred back to community leaders, principally chiefs and pastors, for resolution and reconciliation. The most visible aspect of this to date is the establishment of the position of Community Justice Supervisors (CJS) in the Correctional Services Act of 2006. The supervisors are generally chiefs or pastors and they voluntarily supervise community work sentences handed down by the Court. They are also often involved in the 'pastoral' care of offenders and checking that their relations with the community are harmonious. In many cases they have already been involved with the offender in a kastom process. According to an overseas advisor to the project, ${ }^{9}$ a recent workshop demonstrated that there is "obviously strong support for the model" and his perception was that chiefs feel there is a good fit between the two models (of state justice and kastom conflict management).

This project is an important one given the limited detention facilities in Vanuatu, that are currently overcrowded and have been criticised for human rights abuses (Forsyth 2009: 157-159). In 2010 there were 125 detainees and 260 offenders were being managed in the community by 60 CJSs (Whibley-Smith 2010). Involving the chiefs in probation thus: frees up valuable prison space; reflects the importance of kastom practices in Vanuatu; acknowledges the value, status and knowledge of respected community members; makes the offender accountable to their own community and; contributes to the rehabilitation and reintegration of offenders. CJSs are also functioning as important linkage points between the community and the state justice system (Whibley-Smith 2010). Although there has not to date been detailed research into the efficacy of the program, preliminary research indicates some problems over boundary issues; past issues impacting on CJS/Offender relationship and the other responsibilities of CJSs impeding their work (Whibley-Smith 2010).

\section{(b) Vanuatu Judiciary Conference}

At my suggestion, and facilitated by funding from NZAID, in 2006 the Vanuatu Judiciary held their annual conference on the topic of the relationship between the state justice system and the kastom system at the University of the South Pacific. This was the first time that the judiciary, chiefs, police lawyers and academics had come together to discuss the issues relating to the existence of the two systems of dispute resolution in Vanuatu. As such, it was very much an exploration of the issues involved, a discussion of the possible tensions, and a sharing of ideas about future directions that could be explored. The first part involved a description of the current relationship between the two systems, and was facilitated by a series of papers presented by members of the judiciary, police and the chiefs as well as through group discussion. The point that was emphasized by the Secretary of the NCC and other speakers was that the resources spent on the provision of justice all go to the formal

\footnotetext{
${ }^{9}$ Email correspondence with key informant, 16 June 2010.
} 
system and none to the kastom system, and yet the majority of the population have their disputes resolved by the latter. The second part was devoted to a discussion of the current problems with the relationship, which was managed through a series of papers and then by group discussion in small groups. There was a great deal of agreement amongst the participants in relation to what the problems are, some of the most significant being: lack of communication between the two systems; lack of clear pathways between the two systems; lack of clear guidelines about which system should deal with which cases; the fact that the two systems undermine each other in a variety of ways; and also the problem of people being punished twice for the same offence, once by the state system and once by the kastom system (see Forsyth 2006). The final part of the conference was concerned with a consideration of what steps could be taken to improve the relationship between the two systems and involved small groups considering a series of questions designed to provoke and focus discussion, as well as plenary discussion of the findings of each group. Perhaps unsurprisingly, the participants were far more divided in their views about the possible solutions (Forsyth 2006). For example, when considering the question of sharing of jurisdiction, some groups proposed that the decision of which system should deal with a particular case should rest with the chief. Another group suggested that in urban areas, state law should apply whereas in rural areas, kastom law should apply unless there is no kastom law which covers the situation. Other groups proposed that chiefs should deal with minor matters and the state with serious matters. Some groups felt that kastom should always be used to deal with matters relating to natural resources, even in urban areas. There was also disagreement about whether individuals should have the right to opt-out of being dealt with by the kastom system, with some feeling there should be no opt-out as this undermines the chiefs' authority, while others stated that there should be freedom of choice. Others said that a person should always be able to go to the state system afterwards. Although undertakings were made by chiefs, the police and the judiciary about moving forward with issues identified during the conference (see Forsyth 2006), little headway has in fact been made. Like the action plans in the Kastom Governance project, this demonstrates the important role academics can play in facilitating discussions between different actors involved in conflict management, by creating the space and the conditions for such dialogue to occur. However, it also shows the necessity to have follow up support to assist participants in actioning undertakings made.

The next section proposes a theoretical framework that centres on the creation of linkages in reform and development programming.

\section{A Conflict Management Web Framework}

This section responds to observations such as Baker's (2010: 601) that worldwide there has been "scant understanding of links by the development community and in particular by those engaged in police and justice reform programmes." It proposes a new conceptual framework, the 'conflict management web', to assist international donors and others to understand and work with links in reform in this field. This framework is based upon a number of key insights from network theory (Wellman 1983), nodal governance (Shearing and Wood 2003) and regulatory space metaphors (Scott 2001). It recognises that there are multiple state, non-state as well as hybrid actors (meaning neither fully state, nor non-state) and institutions, which possess a 
range of relevant resources that are currently acting in the conflict management arena, and that there are formal (mandated by state law) and informal relationships or ties between them. It also recognises that these relationships are "complex, dynamic and horizontal" (Scott 2001: 330), and cause the various actors and institutions involved to undergo "processes of assimilation, transformation and adoption" (Baker 2010: 613). Moreover, the relational ties within a network are crucial to determining the "strength, cohesion, collaborative intensity and sustainability" (ibid.: 600) of the network as a whole.

However, the web approach presented here also differs in some respect from these theories. It has an explicitly normative as well as an empirical focus (cf Wellman 1983: 162), as it is geared towards achieving cohesion of the overall structure, not merely to understand the various linkages that exist. Also, unlike classic social network theory, it does not view the attributes of individuals as being less important than their relationships and ties with other actors within the network. Indeed, evidence from fieldwork in Vanuatu suggests that personal characteristics of key individuals are often essential in any development initiative, and are often inextricably linked with their ability to create and maintain relational ties.

The key features of the conflict management web framework are as follows. First, it focuses on identifying, strengthening and, where necessary, building, mutually supporting linkages between different actors and institutions actively involved in conflict management (or indeed any other field). This avoids the adoption of a hierarchical, state-centralist approach to reform and frees up reform initiatives to consider how, for example, state institutions can be positively influenced by and kept in check by non-state actors and institutions (see Scott 2001: 337). It also helps to ensure that agents of reform (be they state governments or international donors) are not duplicating the efforts (or worse, inadvertently undermining the efforts) of another reform project. Second, this framework emphasises the sharing of information about what reform initiatives work and why between various state and non-state actors in the field and also donors, NGOs and academics. This will foster home grown adaptation and innovation to replace the current tendency to look immediately outside for ideas and models. In turn, this is likely to increase the legitimacy of conflict management institutions and actors, which has been identified as an important issue in state-building and reducing conflict and violence (World Development Bank 2011: 84). Action learning and reflection are thus central to the framework, and involve those involved in reform regularly assessing the benefits of their projects to better inform themselves and others in the web about how to implement reforms better. ${ }^{10}$

Third, this framework promotes multiple, small-scale, locally based reform projects, thus taking the focus away from centralised institution-building projects. Ideally, such projects can be on a longer time-scale than would be possible if national coverage were attempted as there will not be as much pressure for short term results as not so much will be riding on the outcome. Small-scale projects can also be intensely local and collaborative and give as much agency as possible to the participants involved to determine the types of reforms to discuss and to implement. An approach that favours multiple projects recognises that many reform initiatives

\footnotetext{
${ }^{10}$ A collaboration-strengthening pyramid such as suggested by Braithwaite (2002: 115 - 127) may also assist in this evaluation and strengthening process.
} 
will fail, and also promotes creative (risky) reform initiatives by not having all of the reforming agency's eggs in the one basket. The World Development Report (World Bank 2011: 32) similarly suggests "pilot many different types of approaches to see which work best; accept a higher failure rate; evaluate rigorously and adapt quickly; and scale up approaches that are working." If many different approaches are tried, the failures of some will be counter-balanced by the successes of others.

Finally, the conflict management web framework promotes a decentralised approach to conflict management, which can be of great use where the state alone does not have the ability (or the will) to meet the conflict management needs of citizens. This works in four ways: it provides alternative paths to conflict management where state courts are over-burdened or non-functional; competition provides incentives to state justice institutions to improve their performance; it can help to avoid the problem of "capture" of donor-funded judicial reform efforts by elites (White 2009); and it can act as a check on power in the hands of a single justice institution where that institution is abusing its power (Braithwaite 1997).

So, what are the actual implications of this for states, international donors and others wishing to undertake justice reform projects? First, it means approaching conflict management reform in a holistic way, taking account of all the actors and institutions involved in the field in a given jurisdiction, including international donors, academics and NGOs. This is an explicit recognition of the political nature of, and role played by, donors in a locally dynamic system. Developing links may be difficult where there are competing agendas at play, or competition for scarce resources (financial or social capital for example), but developing even weak links between competing actors and institutions may foster dialogue that will in the long term produce a more positive relationship between them. Granovetter (2005: 34) argues that greater density of links between nodes "makes ideas about proper behaviour more likely to encountered repeatedly, discussed and fixed." It may also be difficult in countries where customary or religious systems have broken down or are discredited, although there may be other new grass-roots initiatives that have sprung up to replace them. Of course, in situations where there are no viable non-state actors or institutions to work with, the conflict management web framework may not work and it may be necessary to consider a different framework, such as creating a new hybrid structure from scratch.

Second, it means that all projects will need to start with a network analysis of the different institutions and actors involved in conflict management and the links between them. This is more than a standard stocktake of visible actors and formal counterparts, and will inevitably require in-country fieldwork rather than a desk based literature review. As demonstrated above, much of what actually happens in practice in conflict management in developing countries cannot be understood from the literature alone. Relying solely on written materials will prioritise state agencies and may result in overlooking important grass-roots initiatives that could be built upon. This analysis will involve investigating whether any existing institutions or actors have agendas that the particular reform project can strategically align with, before starting to create a new reform project from scratch. It will also mean creating opportunities for dialogues to occur between donors, academics and those involved in conflict management about what initiatives are currently underway and need support, such as the conversation that started the Kastom Governance project. It is also a 
project that requires an anthropological type approach i.e. an understanding of the local political economy and how things actually work in practice in-country, rather than just technical legal skills.

Of course this is likely to be an expensive and time-consuming process and does not easily fit into the current incentive structure for donors (Gibson et al. 2005; World Bank 2011: 26). However, a potential aid may be the tools developed in an IT context to deal with decentralised sources of information, such as a wiki, an interactive website that facilitates the sharing of information by many people. If each country developed a conflict management web wiki that could be used to share information about what projects were happening and reviews of them and associated resources, this would go a long way to reinforcing many existing links between actors and institutions involved in conflict management. It may be that a state government could seek donor funding for establishing and maintaining the wiki, and require everyone involved in the justice sector to keep the site updated as a condition of project approval. Although many rural communities do not have access to the internet, this is changing fast with the huge global expansion of mobile and broadband networks. In Vanuatu, community leaders in even remote areas often have links with people who do have access, and so reliance on a web-based tool will not necessarily exclude more remote actors from the conversation.

One of the major challenges that the conflict management web framework raises is determining what degree of co-ordination and strategic alignment is desirable and practically attainable. The provision of conflict management services often involves local and national political issues, competing agendas, and as demonstrated in section one, different views of what the aims of conflict management should be. Further, having different justice providers can lead to problems associated with forum shopping as discussed above. The question of the governance of networks is a large one and beyond the scope of this article. It seems highly unlikely that any organisation or institution would be willing or able to take on such a role, especially in countries where the state is weak. A single source of oversight may also cut across many of the benefits of the decentralised approach. A better solution in the comparatively simple context of a single nation state is to adopt a self-steering approach (Schout and Jordan 2005) that focuses on developing and strengthening the links between the different actors and institutions involved, both in terms of substantive issues of conflict management and reform project co-ordination. Dialogue about potentially competing reform agendas will promote an articulation of the different agendas at stake, which in turn may assist in finding some middle ground, when all sides see what resources can be fruitfully shared (for example the Kastom Governance project includes gender as an issue that is discussed in the workshops), although this may need time (for example the relative failure of the Chiefs Bill). The more networking and communication that occurs between the actors that engage in spinning different strands of the justice web, the greater is the chance that the web as a whole will have coherence. Braithwaite and Drahos argue (2000: 32) that webs of dialogue are effective for both weak and strong actors and can result in defining a problem, agreeing on principles and rules to solve it, and enforcing those rules "with impressive results."

\section{Conclusion}


This article has argued that two different types of linkages need to be made to improve the quality of conflict management in a country such as Vanuatu, where crucial resources (financial, human, organisational etc) and legitimacy are dispersed between state and non-state institutions. The first type is between those involved in conflict management at both state and non-state levels. Such linkages will facilitate a more effective sharing of resources, as trust and understanding builds between the key actors involved in the administration of each system (Granovetter 2005: 34). The aim is to develop what de Sousa Santos (1987: 298) calls interlegality, where there is "continuous interaction in the main between different legal perceptions, thereby influencing and shaping new normative orders adapted to considering cultural diversity" (Svesson 2005: 51-52). International donors have an important role to play in facilitating these linkages by creating opportunities for dialogue to promote knowledge exchange between key actors, such as the Kastom Governance project and the Judiciary conference.

The second type of linkage that needs to be improved is that between donors, NGOs, state governments and non-state actors and institutions about the different justice reform initiatives that are taking place in a country. This could foster a greater harmonisation of agendas, lessen the risk of one initiative undermining another, allow resources to be used more efficiently, promote discussion about different visions for reform, and help to identify existing initiatives by non-state actors that would benefit from better resourcing.

This article proposes that a conflict management web framework may be adopted as a conceptual and practical tool to assist in developing both types of linkages. This approach is based on analysing the nature and extent of the ties currently linking all actors and institutions involved in conflict management in a particular country, including those who provide material and organisational resources, such as international donors. The understandings gained from such an analysis can then be used to program reform initiatives that can be strategically aligned with autochthonous initiatives currently underway, or which create new linkages that promote a more efficient sharing of the existing resources and social capital. This will increase the chances of any reform fully capitalising on existing resources, being legitimate and sustainable, and being owned and driven by local actors and institutions. 


\section{References}

BAKER, Bruce

2010 'Linking state and non-state security and justice.' Development Policy Review 28: 597-616.

BOEGE, Volker et al

2008 On Hybrid Political orders and Emerging States: State Formation in the Context of 'Fragility' available at http://www.berghof-

handbook.net/documents/publications/boege_etal_handbook.pdf

BRAITHWAITE, John

1997 'On speaking softly and carrying big sticks: neglected dimensions of a

republication separation of powers.' University of Toronto Law Journal 47: 305-361.

BRAITHWAITE, John

2002 Restorative Justice and Responsive Regulation. UK: Oxford University Press.

BRAITHWAITE, John

2008 Regulatory Capitalism: How it Works, Ideas for Making it Work Better. UK:

Edward Elgar.

BRAITHWAITE, John

2010 'Traditional Justice.' Paper presented at the Project on Restorative Justice,

Reconciliation and Peacebuilding at the University of Notre Dame, September 2010.

BRAITHWAITE, John and DRAHOS, Peter

2000 Global Business Regulation. UK: Cambridge University Press

CHANOCK, Martin

2000 'Introduction’ in Sally Moore Law as Process

De SOUSA SANTOS, Boaventura

1987 'Law: A map of misreading; toward a postmodern conception of law.' Journal of Law and Society 14, 279-302.

DINNEN, Sinclair

2003 'Building bridges - law and justice reform in Papua New Guinea.' Pp. 277-303, in Anita Jowitt and Dr Tess Newton Cain (eds.), Passage of Change: Law, Society and Governance in the Pacific. Canberra: Pandanus Books.

FORSYTH, Miranda

2006 Report on the Vanuatu Judiciary Conference 2006: The Relationship Between the Kastom and State Justice Systems. Available at

http://www.paclii.org/vu/2006_jud_conf_report.html

GRANOVETTER, Mark

1973 'The strength of weak ties' American Journal of Sociology 78: 1360-1380.

GRANOVETTER, Mark 
1983 'The strength of weak ties: a network theory revisited.' Sociological Theory 1: 201-223.

GRANOVETTER, Mark

2005 'The impact of social structure on economic outcomes.' Journal of Economic Perspectives 19: 33-50.

GIBSON, Clark et al

2005 The Samaritan's Dilmemma: The Political Economy of Development Aid.

USA: Oxford University Press.

GUPTA, Joyeeta

2002 'Global sustainable development governance: Institutional challenges from a theoretical perspective.' International Environmental Agreements: Politics, law and Economics 2: 361-388.

HESS, Sabine

2005 Person and Place on Vanua Lava, Vanuatu. PhD Thesis. The Australian National University.

HUYSE, Luc and SALTER, Mark Salter (eds)

2008 Traditional Justice and Reconciliation after Violent Conflict (International Institute for Democracy and Electoral Assistance)

LINDSTROM, Lamont

1990 'Straight talk on Tanna.' Pp. 373- 411 in Karen Ann Watson-Gegeo and

Geoffrey White (eds), Disentangling: Conflict Discourse in Pacific Societies.

California: Stanford University Press.

MARANGO, Thompson

2011 'Minimal Budget Hinder Police Operation' Vanuatu Daily Post, Wednesday 9 February 2011, 3.

MERRY, Sally Engle

2006 Human Rights and Gender Violence: Translating International Law into Local Justice. Chicago: University of Chicago Press.

NZ AID,

2005 Proposed Vanuatu Community Probation Service: Summary Report.

NEW ZEALAND LAW COMMISSION

2006 Converging Currents: Custom and Human Rights in the Pacific. Study Paper 17

ODE (OFFICE OF DEVELOPMENT EFFECTIVENESS), AusAID

2010 Vanuatu Kastom Governance Program, Draft Report.

PATERSON, Don

2006 'Customary Reconciliation in Sentencing for Sexual Offences: A Review of Public Prosecutor v Ben and Others and Public Prosecutor v Tarilingi and Gamma' 
Journal of South Pacific Law 10. Available at

http://www.paclii.org/journals/fJSPL/vol10/12.shtml

PATERSON, Don and JOWITT, Anita

2008 'More on customary reconciliation ceremonies in sentencing for criminal offenders.' Journal of South Pacific Law 12/2: 39-47.

Pacific Beat, 'Vanuatu: Chiefs Step in to End Jail-break Impasse,' 10 May 2006, available at http://abc.gov.au/ra/pacbeat/stories/s1635039.htm

SCOTT, Colin

2001 'Analysing regulatory space: fragmented resources and institutional design.'

Public Law, Sum: 329-353

SCHOUT, Adriaan and JORDAN, Andrew

2005 Public Administration 83: 201-220.

SHEARING, Clifford and WOOD, Jennifer

2003 'Nodal governance, democracy and the new 'denizens.' Journal of Law and Society 30/3: 400-419.

SVESSON, Tom

2005 'Interlegality, a process for strengthening indigenous peoples' autonomy: the case of the Sami in Norway.' Journal of Legal Pluralism 51: 51-78.

TOR, Roselyn and TOKA, Anthea

2004 Gender, Kastom and Domestic Violence: A Research on the Historical Trend, Extent and Impact of Domestic Violence in Vanuatu. Vanuatu: Department of Women's Affairs. Available at http://www.vanuatuculture.org/documents/Gender\&Kastom.pdf

WALKER, Polly and GARU, Selwyn 2009 'A few more arrows': Strengthening mediative capacity in Vanuatu.' P.. 94110 in Dale Bagshaw and Elisabeth Porter (eds.), Mediation in the Asia-Pacific region: Transforming conflicts and building peace . London, U.K.; New York, U.S.A.: Routledge.

WELLMAN, Barry

1983 'Network Analysis: Some Basic Principles.' Sociological Theory 1: 155-200.

WESTOBY, Peter and BROWN, Anne

2007 'Peaceful community development in Vanuatu: a reflection on the Vanuatu Kastom Governance Partnership' Journal of Peacebuilding \& Development 3/3: 77 81 .

WESTOBY, Peter

2008 'Dialogue and disentanglement: navigating the territory of diverse discourses of community development within Vanuatu.' New Community Quarterly 6: 81-92.

WESTOBY, Peter 
2010 'Community-based training for conflict prevention in Vanuatu: reflections of a practitioner-researcher.' Social Alternatives 29: 15 - 18.

WHIBLEY-SMITH, Angela

2010 'Community Justice Supervisors: Incorporating Kastom into Vanuatu Probation' Powerpoint presentation on file with author.

WHITE, Geoffrey and LINDSTROM, Lamont (eds)

1994 Culture, Kastom, Tradition: Developing Cultural Policy in Melanesia. Hawaii: The East-West Centre

WHITE, Brent

2009 'Rotten to the core: project capture and the failure of judicial reform in

Mongolia.' Arizona Legal Studies Discussion Paper No. 09/24.

WORLD BANK

2011, World Development Report: Conflict Security and Development, available at http://wdr2011.worldbank.org/sites/default/files/pdfs/WDR2011_Full_Text.pdf 